Journal of Agricultural Sciences
(Tarim Bilimleri Dergisi)

\title{
Production of Agricultural Biodegradable Mulch and Evaluation it through Heat and Moisture Distribution in Soil
}

\author{
Mohammad SHAHABI ${ }^{a} \mathbb{D}$, Mehdi KHOJASTEHPOUR ${ }^{a^{*}} \mathbb{D}$, Hassan SADRNIA $^{a}$ (D) \\ ${ }^{a}$ Department of Biosystems Engineering, Ferdowsi University of Mashhad, Mashhad, IRAN \\ ARTICLE INFO \\ Research Article \\ Corresponding Author: Mehdi KHOJASTEHPOUR, E-mail: mkhpour@um.ac.ir \\ Received: 14 March 2020 / Revised: 27 May 2020 / Accepted: 03 June 2020 / Online: 04 September 2021
}

\section{ABSTRACT}

The need to increase agricultural production in proportion to population growth and water crisis management requires initiatives that can increase the quantity and quality of crops by using soil moisture storage methods while preserving the environment. According to problem presented, in order to simulate the temperature, humidity and radiation of the farm environment, a control system, along with laboratory facilities were designed and constructed. Then, the production and evaluation of different types of soil mulches from biodegradable and petroleum polymers were performed by aiming investigate the effect of these soil mulches on soil temperature and moisture at different depths. Produced mulches were placed in a laboratory soil bed. The average molecular weight, the gel content and the percentage of elongation at the breakpoint for biodegradable mulches were $4906.56 \mathrm{~g} \mathrm{~mol}^{-1}, 4.68 \%$ and $4.63 \%$, respectively and the mean values of tensile strength and the percentage of elongation before the ultraviolet aging process were $13.41 \mathrm{MPa}$ and $396.71 \%$, respectively. Acceptable values of statistical indicators were calculated with the response surface method. In conclusion of the soil temperature and humidity changes for different types of mulch, the velocity of temperature rise is reduced in deep levels due to the resistance made by soil moisture. The amount of moisture reduction for dark and uncoated mulch by moving from surface to depth was far more when compared to other mulches, and there was no significant change at the depth of transparent mulches.

Keywords: Response surface method, Soil moisture, Soil temperature

(C) Ankara University, Faculty of Agriculture

\section{Introduction}

With the reduction of fossil resources and increase of human-made and environmental hazards, researchers are now looking for alternatives to replace plastic products. Bioplastics, which are biodegradable and destructive, have the same properties as plastics. They also have additional properties, including carbon footprint and organic biomarkers.

Soil temperature is an important control parameter in agriculture, which is more important than environment temperature. (Pramanik et al. 2015). The use of mulch in agricultural fields is a technique for saving water and controlling temperature and garden pests (Schonbeck \& Evanylo 1998). For better performance of agricultural products, the approximate temperature in soil was changed from 25 to $32{ }^{\circ} \mathrm{C}$, and it is recommended to apply 8 and $15{ }^{\circ} \mathrm{C}$ for increasing the root thickness (Tindall et al. 1991). In addition, controlling the temperature of the plant root can prevent the emergence of plant diseases and lead to premature production (Díaz-Pérez et al. 2007). The required actual amount of heat at times varies with the physiological conditions of the plants. Heat requirement is often expressed in GDD or GDH. Therefore, with having sufficient information about minimum and maximum temperatures for different plants in different physiological conditions and with meeting their thermal requirements, it is possible to avoid loss of energy and plant degradation.

Considering the increasing environmental pollution and the depletion of fossil resources, a growing number studies over the past few years have attempted to replace synthetic plastics derived from petroleum compounds with plastics made from renewable sources. This product was developed in the early 1980`s with starch-based compounds and fat polyesters (such as poly hydroxy butyrate or polyacetate) (Zhang et al. 2008). Oxidation and extract water and carbon dioxide from the polymeric material resulted from breaking the molecular coarse chains into smaller components in these polymers (Fattahi 2015).

Tensile characteristics and functional characteristics, including water vapor evaporation and optical characteristics were studied while they were being used in farms. Despite the fact that the mechanical properties of the destructive mulch were reduced after only five months, they met the farms functional requirements and finally became known as a suitable substitute for polyethylene in grape fields (Touchaleaume et al. 2016). 
The degree of degradability is another topic that has been studied in this domain of research (Kyrikou \& Briassoulis 2007; Sivan 2011; Li et al. 2014). In order to determine the degradability, different types of biodegradable mulch were used and they were then compared with conventional types of polyethylene mulch. The effect of isopods showed that the disintegration rates of starch- and cellulose-based plastics increased (Wood \& Zimmer 2014).

Another method in studying the effects of mulch on the growth process is radiation measuring solarization. Also, a comparison of transmission, reflection and absorption rays of the sun in short and long wavelengths was made (Papadakis et al. 2000; Scarascia-Mugnozza et al. 2004; Heißner et al. 2005). The results of this research showed that the biodegradable mulch used with the maximum transmission of the solar spectrum and the minimum infrared spectrum can increase the temperature of the soil bed. In addition, it may prevent the passage of the photosynthetic spectrum to reduce the growth of weed (Vox \& Schettini 2007).

Two variables of reflectance and radiation transmission coefficients in the mulches were identified as important parameters in soil temperature identification. However, there was a significant difference between the measured and calculated values of temperature by model for the transparent film due to the air layer between the soil and the mulch (Ham et al. 1993; Ham \& Kluitenberg 1994; Heißner et al. 2005).

Therefore, reliable results were obtained by designing an experimental set-up with a control over all parameters that will be measured in this study. In this research, by creating an appropriate experimental environment, the soil moisture and temperature changes under the mulch were investigated with a quasi-solar thermal source. Previous studies had relied on standard methods for degradability, which was also used in the present research (Mortazavi et al. 2013; Akrami et al. 2016). In this study, the verification tests of mulch degradability were also carried out.

\section{Material and Methods}

\subsection{Preparation of mulch films}

The mulch films were produced from the raw material of LDPE and color additives were produced in Imam Petrochemicals Port. For all types of Oxo-biodegradable, an additive was used that combines the salts of fatty acid (50 to 70\%), rare compositions of earth (10 to $20 \%)$ and lubricants (10 to $20 \%)$ from P-Life Japan Inc.

The first stage of the production included mixing the granules with a ratio of 100 and 3 phr for LDPE and the additive, respectively. In the next step, the mixture was extruded. The extruder was set to gradually increase the initial temperature to 140, $150,155,160$, and $165^{\circ} \mathrm{C}$ and the rotational speed of the co-rotating twin screw was set to $150 \mathrm{rpm}$ by the ZSK extruder. The thin films were prepared using film blowing machine (Coline BL 180/600) by adjusting the temperature of the device at 8 points: 140 to 175 at intervals of $5{ }^{\circ} \mathrm{C}$ and adjusting spiral of 25 to $30 \mathrm{rpm}$. The average film thickness was obtained according to the ISO 4593 standard at 10 points (ISO 1993).

\subsection{Degradability tests}

In this test, the samples were exposed to the UV-light type A (at a wavelength of $340 \mathrm{~nm}$ ) with a radiation intensity of $0.89 \pm$ 0.02 watts $\mathrm{m}^{-2} \mathrm{~nm}^{-1}$ in accordance with the ASTM D-5208 standard for 200 hours at $50{ }^{\circ} \mathrm{C}$ (ASTM 2014). The accuracy of mulch degradability is determined by examining the weighted average of $\mathrm{Mw}$, gel content and elongation at the breakpoint of samples after the aging test.

The weighted average molecular mass was determined according to ASTM D6954 and the method of gel permeation chromatography. The apparatus used in this experiment was PL GPC 220 and TCB solvent was used at $160^{\circ} \mathrm{C}$. To prevent the degradation of the polymer during the test, antioxidant of BHT was added to the mixture. (ASTM 2004). The gel content was measured according to the ASTM D 2765-1 standard so as to determine the portion of the polymer that becomes crosslink in an abiotic destructive process, which is unsolvable (ASTM 2006). Initially, in this method, a sample with a specified mass of residual materials from the abiotic destructive test was immersed in a boiling solvent P-Xylene for 12 hrs, while it was inside the 120 steel wire mesh. During this period, the soluble part of the sample is dissolved in the solvent and only the insoluble portion (gel) remains inside the wire grid. The remaining mass of the sample is determined by weighing after removing the grid and drying it. Finally, the gel content of the sample is obtained according to the Equation (1):

$\%$ gel $=\left(W_{2} / W_{1}\right) * 100$

$\mathrm{W}_{1}$, is the initial sample weight and $\mathrm{W}_{2}$, is the residual weight of the sample after being placed in the boiling solvent.

Test conditions for measuring the tensile properties of plastic films with thickness less than $1 \mathrm{~mm}$ has been determined according to the principles of ISO 572-3. The Tinius Olsen H5KS from England was used to carry out the tensile tests. 


\subsection{Experimental Setup}

In order to simulate the test conditions on agricultural mulches and in accordance with open space and to create the same conditions for all experiments, an environment was created with the control of the temperature and intensity of electromagnetic radiation. To achieve this goal, an isolating chamber was used to adjust the temperature and ventilation and a test system was placed inside the chamber. The design and construction of all the above mentioned equipment was carried out at the laboratory of Department of Biosystems Engineering, at Ferdowsi University of Mashhad. The temperature of the isolation chamber was adjusted by a temperature controller of the Samwon SU-105 model and the cooling and heating system were connected to it. Therefore, the only heat source delivered to the surface of the soil was electromagnetic waves from the bulbs. The test system includes a soil bed with typical traits for the plant cultivation. The sidewall and floor of the soil bed were covered with thermal insulation from EPS of a thickness of $60 \mathrm{~mm}$.

The distribution of the heat at various depths of the soil with the highest accuracy demands a lot of temperature sensors at certain intervals from each other and in different parts at each level from the depth. In this research, three temperature sensors of DS18B20 have been used for every depth level. The water-proof model of these sensors is placed at the desired depth to measure the temperature which has relatively high moisture content. Also, the four depths were defined between 0 and $40 \mathrm{~cm}$ (Figure 1).

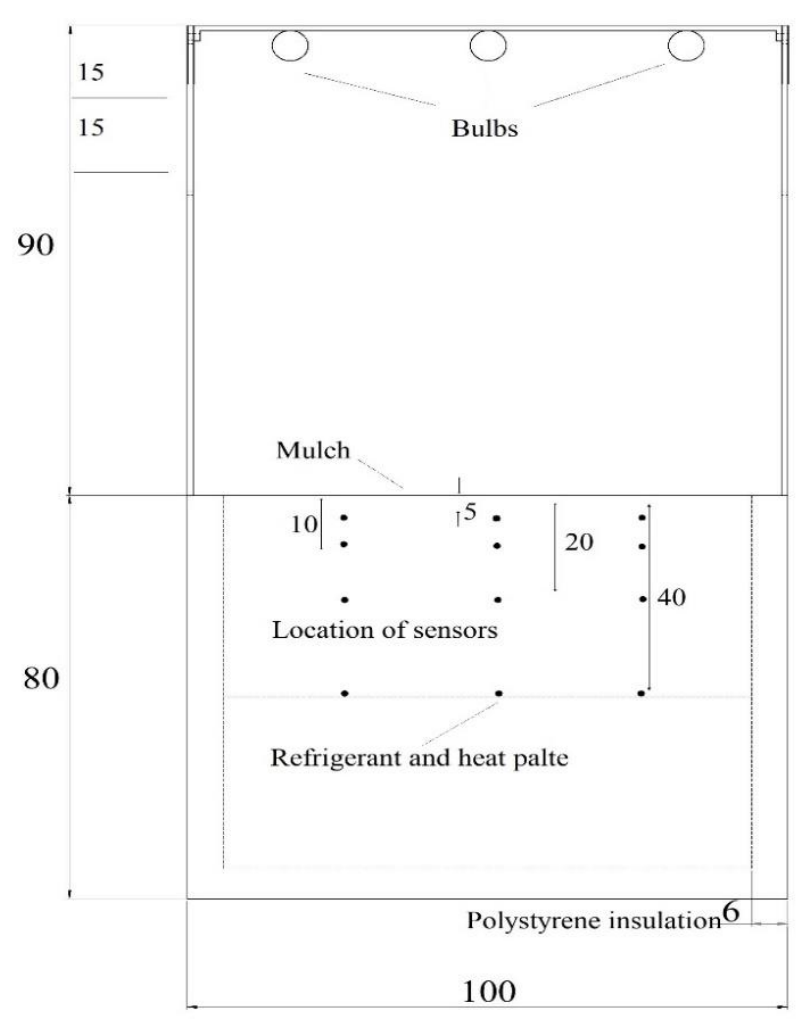

Figure 1- Designed system for evaluation of the mulch by examining the thermal distribution and soil moisture distribution (Measures in $\mathrm{cm}$ )

The YL-69 moisture sensor was used to measure moisture content at three depths. Because the AW in agricultural activities should be between FC and PWP, was tried to set the soil moisture content in this range at the start of the experiments. Each of FC and PWP values were calculated using PTF provided by Mohanty et al. with coefficients of 0.9 and 0.84 , respectively. (Mohanty et al. 2015). Temperature and moisture changes in the soil were recorded at different depths during the experiment at specified intervals.

The high-pressure sodium lamp was used to simulate the solar radiation which perfectly match the photosynthetic range of solar radiation when compared with other lamps.

The Kipp \& Zonen Pyranometer CMP3 model was used to determine the proper location of the bulbs so that the intensity of the radiation can be constant across all parts of the surface. Given the average sunlight during sun hours in the area under study (Khorasan-e Razavi: Iran: 250 to $350 \mathrm{~W} \mathrm{~m}^{-2}$ ), the minimum, average and maximum values of the radiation intensity at 60,75 and $90 \mathrm{~cm}$ heights of the bulbs were selected from the soil surface through measuring the amount of radiation from the bulbs at 3 points in the soil surface. This radiation range has also been used in previous studies (Braunack et al. 2015; Shakeri 2016). 
The actual view of the isolation chamber and the equipment used in the test system are shown in Figure 2. At the start of experiment, the temperature and humidity of the whole soil bed are set at a specific point so that the changes in heat and moisture caused by the radiation can be analyzed. During the experiment, a refrigerant system was prepared and it was tried to maintain a constant temperature at a depth of $40 \mathrm{~cm}$ and to create boundary conditions at this depth. To achieve this, the cooling circuit was activated with water. Both the thermal and refrigerant systems were connected to a temperature controller of the Samwon SU-105 model and at the set point commands were issued to set up each of the thermal and refrigeration systems.
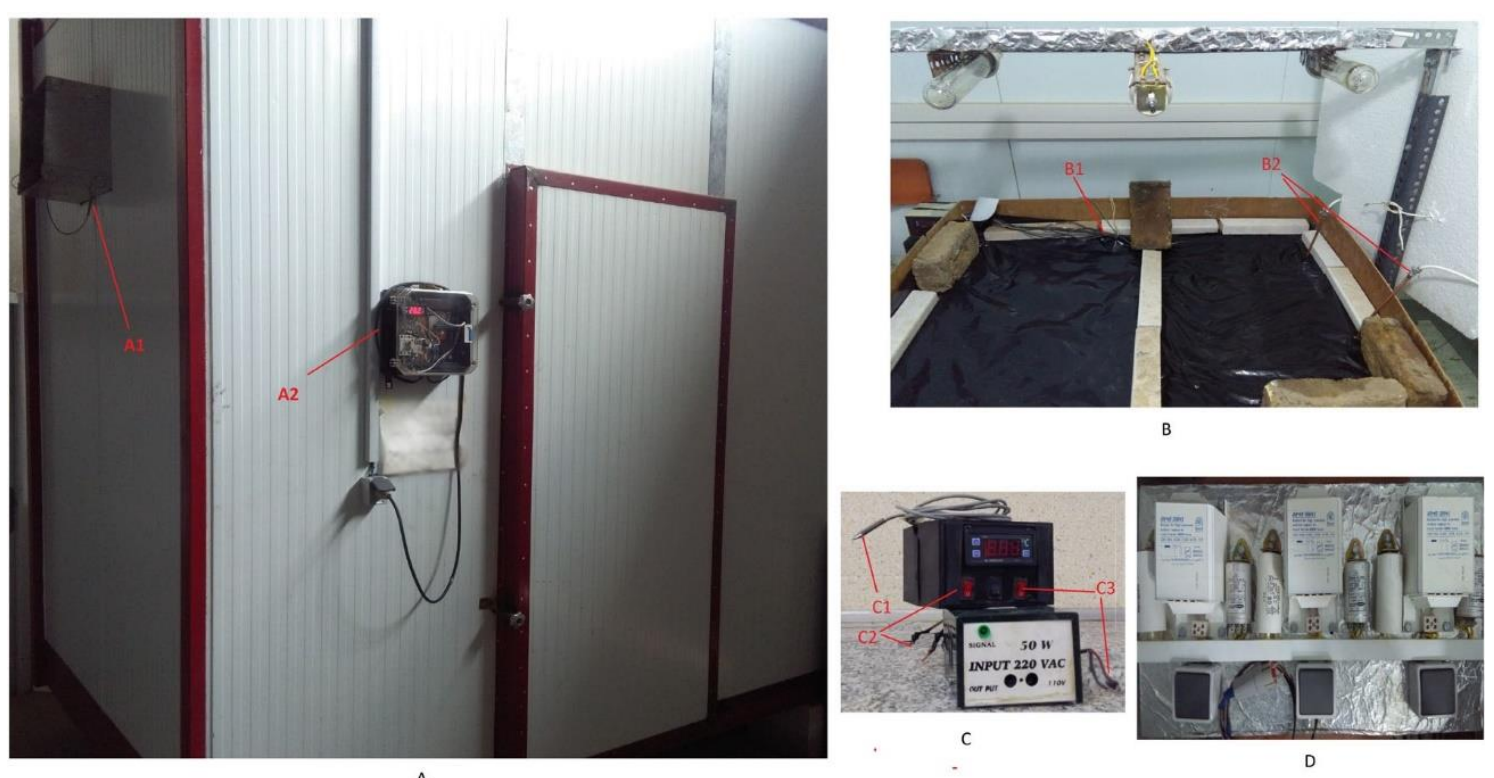

Figure 2- Representation of the equipment used in conducting experiments to record the changes in soil temperature and humidity. A: Temperature isolation chamber (A1: Air conditioning fan A2: Electronic board setting of temperature and startup of heating and freezing system). B: The space above the soil bed (B1: The location of the connection cables to the sensors B2: The entrance of refrigerant pipes to a depth of $40 \mathrm{~cm})$. C: The system for installing a heating and freezing system at a depth of $40 \mathrm{~cm}(\mathrm{C} 1$ : PT100 temperature sensor, C2: key and connection to the coolant flow regulator pump, C3: key and connection to the thermal plate embedded at a depth of $40 \mathrm{~cm}$ ). D: Electric circuit for HPS bulb startup: Capacitor, ballast and Igniter for each bulb

The produced mulch films spread over the surface of soil and the irradiation system and data recording was launched. The temperature of the chamber, that embraced the experimental system, was kept unchanged until the end of experiment so that only the HPS light bulbs can be affected and the effect of surrounding temperature was neutralized $\left(25^{\circ} \mathrm{C}\right)$. The experiment lasted until the different surface temperatures in the soil bed reached a fixed point, which occurred approximately after 48 hours.

\subsection{Experimental design and statistical analysis}

The experimental design used in this study was the Response Surface Method with the face composition central design (FCCD), which is widely used among the response surface methods (Bas \& Boyaci 2007). Independent variables were coded at three levels of $-1,0,+1$ and the experiments were performed at a central point with five replications (Table 1).

Table 1- Coded levels of values of independent variables

\begin{tabular}{ccccc}
\hline Independent variables & symbol & -1 & 0 & 1 \\
\hline Radiation Intensity $\left(\mathrm{w} / \mathrm{m}^{2}\right)$ & A & 250 & 300 & 350 \\
\hline Time $(\mathrm{h})$ & B & 12 & 30 & 48 \\
\hline
\end{tabular}

In this research, equation (2) was used to determine the relationships between independent variables (numerical variables, including intensity of electromagnetic radiation in 250,300 and $350 \mathrm{~W} \mathrm{~m}^{-2}$, duration of radiation at 12,24 and 48 hours, and nominal variables, such as the mulch type in four levels like transparent, dark, biodegradable and uncoated surfaces) with the predicted response (the soil temperature at depths of $0,10,20$, and $40 \mathrm{~cm}$ ):

$$
Y=b_{0}+\sum_{j=1}^{k} b_{j} x_{j}+\sum_{j=1}^{k} b_{j j} x_{j}^{2}+\sum \sum_{i<j}^{k} b_{i j} x_{i} x_{j}
$$


Where; $y$, is the predicted response; $b_{0}$, is the constant coefficient; $k$, is the number of independent variables; $b_{i}$, linear effects; $b_{j j}$, is the effect of squares; $b_{i j}$, is interaction effects, and $x_{i}, x_{j}$ are independent encoded variables.

The fitting of response levels and the significance of model coefficients were determined by the analysis of variance per response in Design Expert 10 software. The validity of model was evaluated using R-squared, R-adj and CV.

To comparison of the mean of the different levels of each treatment was also made by Minitab 17 software so as to evaluate the moisture changes during the experiment as well as in different depths of the soil.

\section{Results and Discussion}

\subsection{Molecular weight distribution}

The results of variations in the concentration of test solutions during the retention time (exit from the device column) are represented in Figure 3. Since smaller particles of the solution are placed in the stationary phase cavities of the device and then they cross through the gaps, so time out of the device becomes longer. Therefore, the distribution of the solution concentration in the outlet solution can show the distribution of molecular mass of solutions very well. The mean number of $M n$ was used to determine the flexibility and viscosity. An accurate assessment for the relative amount of materials with higher molecular weight, which has a high contribution in the physical properties of polymer, was measured by the weighted average of $M w$. Weighted average of $M z$ was used to detect the presence of materials with very high molecular weights. $M v$ and the average viscosity to molecular weight are correlated. The molecular weight distribution index of PDI indicates the heterogeneity of the sample and this ratio is close to one of homogeneous polymers (Equations. 3-7). The molecular weight was calculated and the percentage of the distribution below the distribution graph in each molecular weight range is presented in Table 2 and Table 3 respectively.

$$
\begin{aligned}
& P D I=\frac{\bar{M}_{w}}{\bar{M}_{n}} \\
& \bar{M}_{v}=\left[\frac{\sum_{i=1}^{N} H_{i}\left(M_{i}\right)^{\alpha}}{\sum_{i=1}^{N} H_{i}}\right]^{1 / \alpha} \\
& \bar{M}_{z}=\frac{\sum_{i=1}^{N} H_{i}\left(M_{i}\right)^{2}}{\sum_{i=1}^{N}\left(H_{i} M_{i}\right)} \\
& \bar{M}_{w}=\frac{\sum_{i=1}^{N}\left(H_{i} M_{i}\right)}{\sum_{i=1}^{N} H_{i}} \\
& \bar{M}_{n}=\frac{\sum_{i=1}^{N} H_{i}}{\sum_{i=1}^{N}\left(H_{i} / M_{i}\right)}
\end{aligned}
$$

Where; $\mathrm{H}_{\mathrm{i}}$, is the height of the GPC curve and $M i$, is the molecular weight of substance washed in i-th magnitude of the inhibitory volume and $\alpha$ is the Mark-Houwink coefficient.

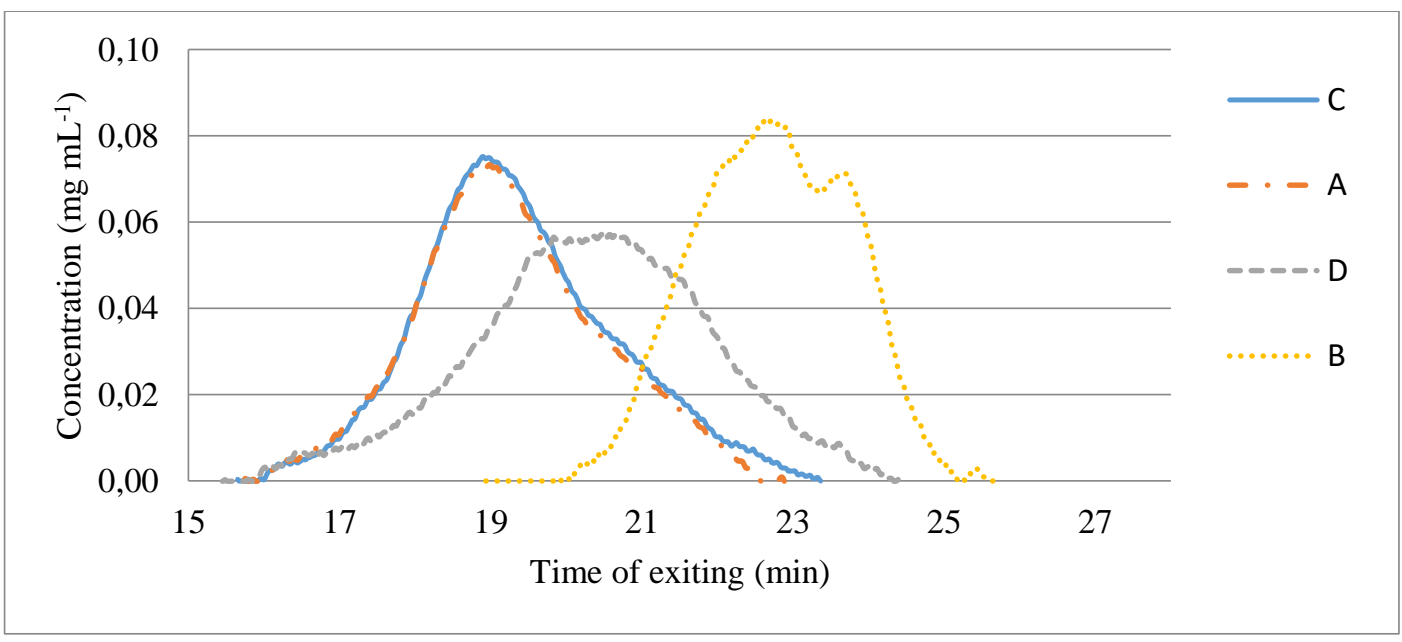

Figure 3- Changes in the concentration of solutions during exiting from the GPC device. A: with biodegradable additive and no UV aging, B: with biodegradable additive and UV aging, C: no biodegradable additive and no UV aging, D: no biodegradable additive and with UV aging 
Table 2- The values of the average molecular weight calculated on the basis of g.mol $^{-1}$ and the distribution index of molecular weight and the Mark-Houwink coefficient of GPC detector

\begin{tabular}{ccccccc}
\hline Mulches & $M n$ & $M w$ & $M z$ & $M v$ & $P D I$ & $\alpha$ \\
\hline No additive & 23696.6 & 142174 & 487420 & 93850.1 & 5.99979 & 0.4457 \\
With additive & 26499.4 & 169563 & 671216 & 96978.4 & 6.39875 & 0.3453 \\
No additive and with UV aging & 8482.23 & 119533 & 937725 & 51743.4 & 14.0922 & 0.4143 \\
With additive and UV aging & 1375.58 & 4906.56 & 13445 & 3147.69 & 3.5669 & 0.3021 \\
\hline
\end{tabular}

Table 3- Percentage range for distribution of average molecular weight (A: with biodegradable additive and no UV aging, B: with biodegradable additive and UV aging, C: no biodegradable additive and no UV aging, D: no biodegradable additive and with UV aging)

\begin{tabular}{cccccc}
\hline \multicolumn{2}{c}{$M w\left(\mathrm{~g} \mathrm{~mol}^{-1}\right)$} & \multicolumn{5}{c}{ Sample value in range $(\%)$} \\
\hline Lower range & Upper range & $A$ & $B$ & $C$ & $D$ \\
\hline $1 \mathrm{E}+6$ & $5 \mathrm{E}+6$ & 2.61 & 0 & 1.522 & 2.63 \\
$1 \mathrm{E}+5$ & $1 \mathrm{E}+6$ & 39.65 & 0 & 38.62 & 19.13 \\
$1 \mathrm{E}+4$ & $1 \mathrm{E}+5$ & 47.83 & 13.65 & 49.56 & 51.17 \\
1000 & $1 \mathrm{E}+4$ & 9.88 & 62.42 & 10.27 & 25.25 \\
72 & 1000 & 0 & 23.91 & 0.009 & 1.8 \\
\hline
\end{tabular}

The advantage of using the GPC method with triple detectors (light scattering, differential refractive index, and viscometer), in comparison with similar methods, such as static light scattering and osmometry, lies in the fact that not only does this method determine the average value of molecular weight, it also facilitates the full distribution of the material. Given that each part of the distribution graph of concentration represent a specific feature of solution, the physical and mechanical properties of the solutions can be obtained by calculating each the weighted average parameters. As already mentioned in the existing literature, the use of the GPC method is necessary, compared to other chromatographic methods. This is due to the existence of tight and long chains in LDPE polymers. The values obtained for the mean of molecular weight and Mark-Houwink coefficients with different solvents (TCB and DBM) are in line with those of previous studies (Coto et al. 2007; Boborodea et al. 2015). According to ASTM D6954 for thin films, when passed the UV aging period, biodegradable mulches must gain average weight-average molecular weight (MW) of $5000 \mathrm{~g} \mathrm{~mol}^{-1}$ or less. According to Figure 3, since solutions "B" and "D" stayed inside the device a long time, they will have smaller particles and will definitely have a lower average molecular mass. Also, about $63 \%$ of the particles of "B" sample were in the range of 1,000 to 4,000 and the rest was less than $5000 \mathrm{~g} \mathrm{~mol}^{-1}$. Therefore, one of the conditions for bio-degradability was met in the mulch type produced in this experiment. In this type of LDPE mulch about $23 \%$ of the particles were higher than $5000 \mathrm{~g} \mathrm{~mol}^{-1}$.

\subsection{Gel content}

Gel formation is a frequent side reaction of the oxidative degradation in polymers, especially polyolefin. Gels are cross-linked structures resulting from the free radical nature of oxidative degradation. They are insoluble in nonreactive solvents, which do not break additional bonds. Normally, gels are not available to biodegradation. Some gels dissolve into further oxidative degradation and become available for ultimate biodegradation. However, the pro-oxidant (catalyst) may be excluded from the gel structure because of solubility changes in the gel phase. In this case, the gel would become a non-degradable or very slowdegradable new fraction within the polymer. It is important to establish the extent of gel and its nature or permanence in the polymer residue (ASTM 2004). The comparison of four different groups in samples which were produced with three replicates per group is presented in Figure 4. This is for determining the residual content of the insoluble matter, which results from the gel content test. The results showed that the percentage of residual samples which are not under ultraviolet aging and lack biodegradable additives is more than other samples. The functional properties of polymer obtained from cross linking, based on the determination of gel content, can be specified and reviewed. Therefore, with the increase of the additive of Dicumyl peroxide as a cross linking agent, the percentage of gel content increases. There is a probability of degradation in the sample with less than $5 \%$ of non-solvents and with an additive after being exposed to ultraviolet aging.

Gels are cross-linked polymer structures, which are insoluble in solvents, and they do not break the primary or cross-linking bonds in the polymer. Cross-links were created during Oxo-biodegradation of polymers. Chemical bonds, especially carboncarbon bonds are created by the degradation process, and consequently, they extremely resistant to solvent degradation. The results of this study indicated that the used additive could not create a crosslinking among the polymeric chains of the production. Therefore, the percentage of residual non-additive samples was even higher than the biodegradable samples given the aging condition. The reduction of gel content suggests that additive molecules have created covalent bonding among the base form of polymer molecules. These materials lead to the loosening of polymeric chain, and consequently, the residual percentage of the sample is reduced when it is placed in a hydrocarbon solvent solution. This indicates the natural behavior of linear viscoelasticity at the end points of the chains (Zhang et al. 2012). 


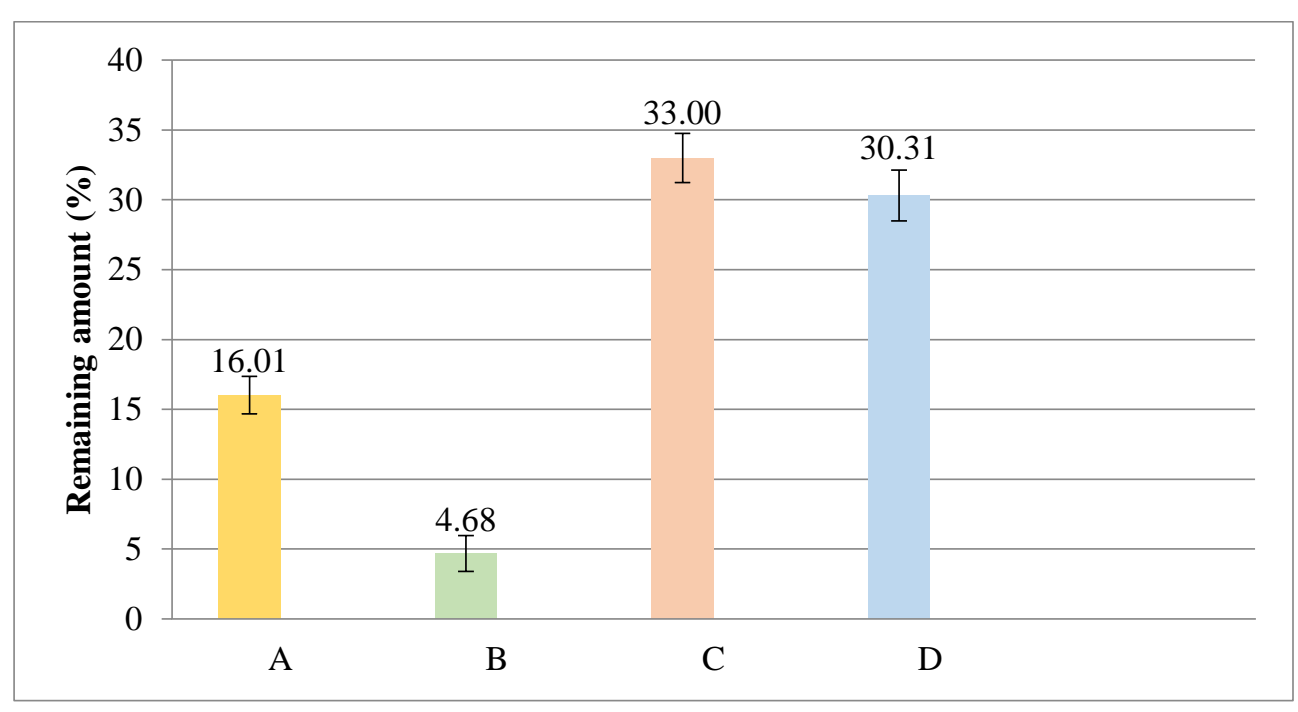

Figure 4- Results of testing the gel content of the produced samples (A: with biodegradable additive and no UV aging, B: with biodegradable additive and UV aging, $\mathrm{C}$ : no biodegradable additive and no UV aging, D: no biodegradable additive and with UV aging)

\subsection{Tensile test}

According to the European Standard EN 13655, in order to maintain mulch integrity in the field and to deal with environmental damage (resulting from wind, rain or animals) a minimum value of resistance was defined i.e., tensile strength and elongation at breakpoints of $12 \mathrm{MPa}$ and $200 \%$, respectively (Takahashi 2007). This should be noted that this is a prerequisite for the use of agricultural mulches. If biodegradable mulch is used, the results gained from the ultraviolet aging test should also be taken into account. The elongation at breakpoint concerning at least $75 \%$ of tested specimens in the initial strain was expressed in a standard below 5 percent ( $\mathrm{Wu}$ et al. 2004). The results of the tests are shown in Figure 5 at the moving speed of $50 \mathrm{~mm}^{\mathrm{min}} \mathrm{m}^{-1}$ with the moving upper jaw and the constant lower jaw of the strength measuring device.



\section{Figure 5- Chart of variation percentage increase in length and tensile strength at break point in pre and post ultraviolet aging conditions}

The addition of the biodegradable additives decreased the strength of the samples. Incorporating these compounds into strong hydrogen bonding in polyolefin compounds can decrease the strength of polyethylene chains and affect the mechanical properties (ASTM 2018). However, it should be noted that with the addition of these additives, a special feature is gained in the mulch, which is far more important than the amount of reduced strength. In fact, as can be seen in the results, the mechanical properties obtained from the additive samples are higher than the minimum requirements of EN 13655 and there will be no problem in using these products. The biodegradable product in the present study has a higher mechanical strength, as opposed to other products presented in previous similar reports (Briassoulis 2004, 2006). Sample test results conform to the ASTM D6954 standard when they are aged under the conditions of biodegradability of the samples (ASTM 2004). Despite the fact that the tensile strength of the LDPE mulch has reached the specified range for biodegradability after UV aging (4.21 $M P a)$, but the elongation at the breakpoint failed to reach the required range. 


\subsection{Heat and moisture changes in the soil bed}

According to the results of variance analysis of temperature and humidity at different levels of soil by the response surface method, a significant difference was observed at $5 \%$ level for the tested mulches (Figure 6, Figure 7, Figure 8). The comparison of temperature variations at different levels of soil indicated that with the increase of soil depth, the amount of heat penetration decreases as Figure 8 and Figure 9 illustrate. Acceptable values for the statistical indices were calculated through the response surface method. The aim was to predict temperature variations at different soil levels for different mulch types. This method was effective in terms of reducing the number of experiments and saving time (Table 4 and Table 9).



Figure 6- Moisture changes during the test run time for different mulches

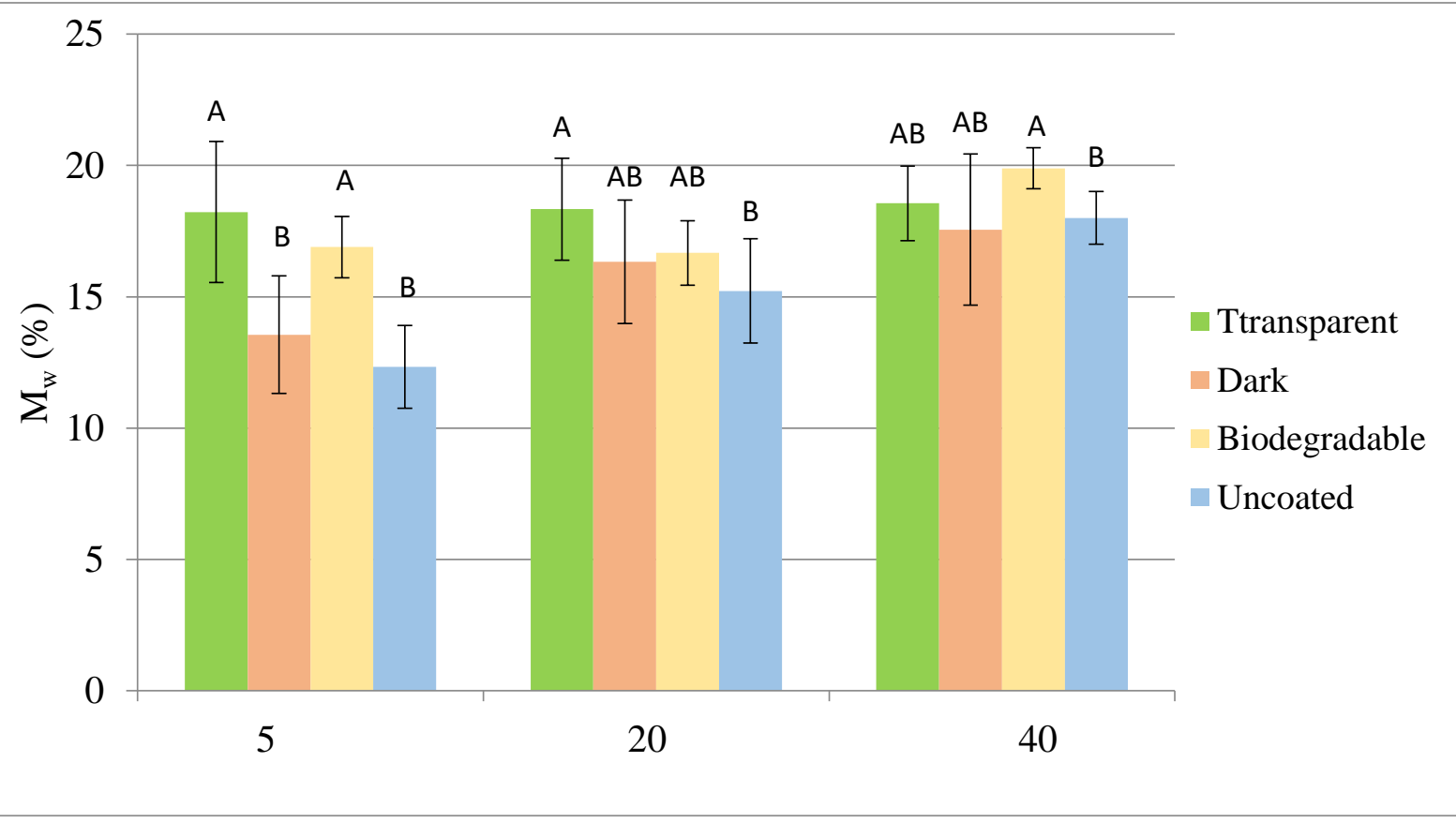

Figure 7- Moisture changes during the experiment at different depths of soil in different mulches 


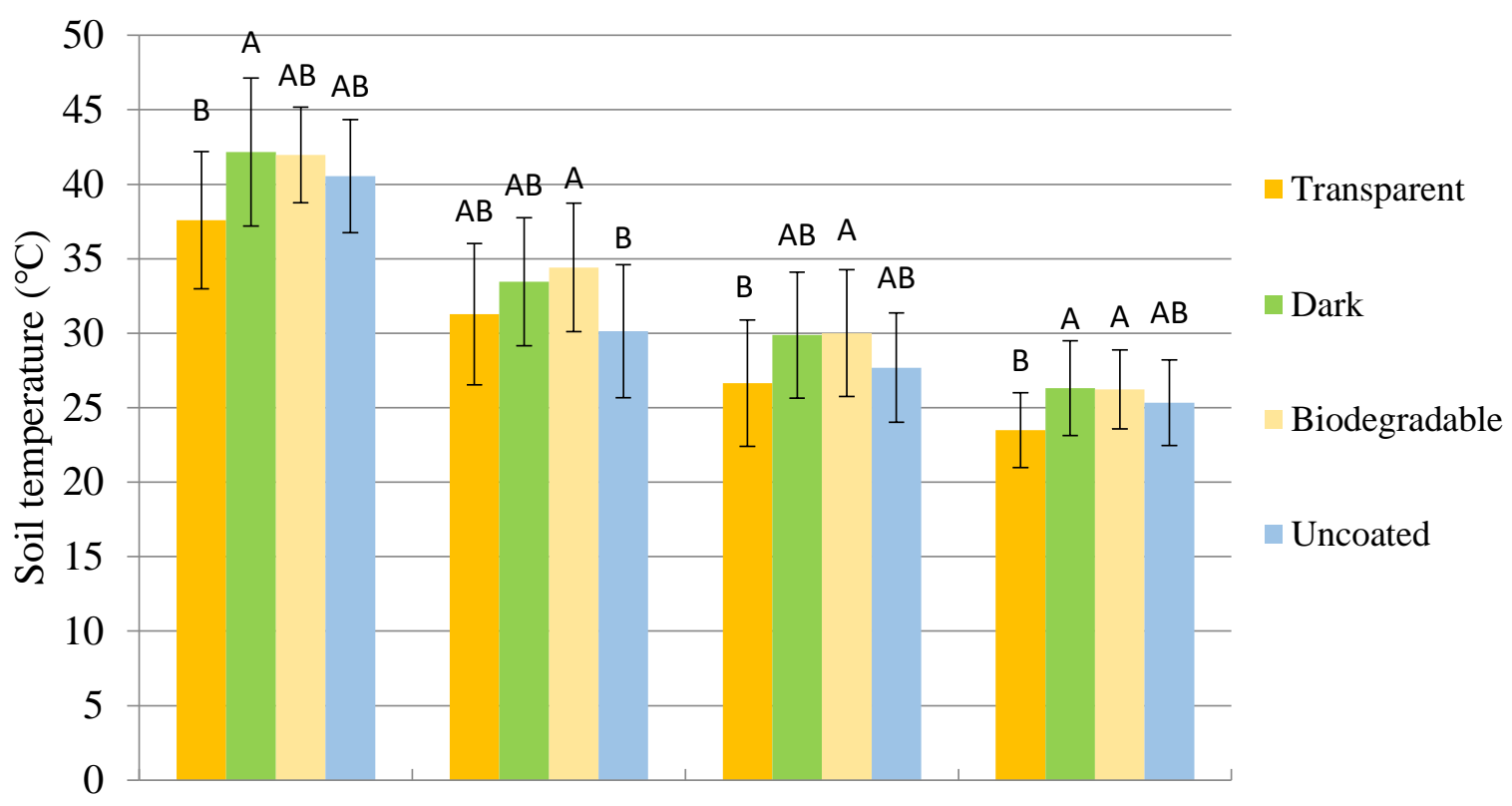

Figure 8- Temperature variations at different depths for different mulches

Table 4- Extraction results based on the response level for the statistical index and predicted equations for temperature in different depth of soil. A: intensity of radiation $\left(\mathrm{w} \mathrm{m}^{-2}\right)$. B: Radiation duration (hr)

\begin{tabular}{|c|c|c|c|c|c|}
\hline & & \multicolumn{4}{|c|}{ Depth (cm) } \\
\hline & & 0 & 10 & 20 & 40 \\
\hline \multirow{5}{*}{ 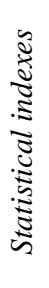 } & Mean & 40.57 & 32.32 & 28.56 & 25.34 \\
\hline & Std. Dev. & 1.03 & 0.66 & 0.73 & 1.11 \\
\hline & $R$-Squard & 0.9678 & 0.9877 & 0.9819 & 0.9224 \\
\hline & $A d j-R-S q u$ & 0.9470 & 0.9798 & 0.9703 & 0.8587 \\
\hline & C.V. \% & 2.54 & 2.04 & 2.56 & 4.40 \\
\hline \multirow{4}{*}{ 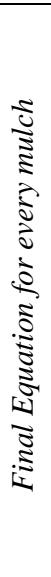 } & Black & $\begin{array}{c}\mathrm{T} 0=- \\
199.04+1.48 * \mathrm{~A}+0.51 * \mathrm{~B}- \\
1.87 \mathrm{E}-04 * \mathrm{~A} * \mathrm{~B}-2.33 \mathrm{E}- \\
03 * \mathrm{~A}^{2}-4.67 \mathrm{E}-03 * \mathrm{~B}^{2}\end{array}$ & $\begin{array}{c}\mathrm{T} 10=55.54+0.49 * \mathrm{~A}+0.53 * \\
\mathrm{~B}+4.920 \mathrm{E}-04 * \mathrm{~A} * \mathrm{~B}-7.89 \mathrm{E}- \\
04 * \mathrm{~A}^{2}-6.47 \mathrm{E}-03 * \mathrm{~B}^{2}\end{array}$ & $\begin{array}{c}\mathrm{T} 20=- \\
86.29+0.7 * \mathrm{~A}+0.28 * \mathrm{~B} \\
+7.72 \mathrm{E}-04 * \mathrm{~A} * \mathrm{~B}-1.17 \mathrm{E}- \\
03 * \mathrm{~A}^{2}-3.89 \mathrm{E}-03 * \mathrm{~B}^{2}\end{array}$ & $\begin{array}{c}\mathrm{T} 40=-59.75+0.58 * \mathrm{~A}- \\
0.17 * \mathrm{~B}+6.6 \mathrm{E}- \\
04 * \mathrm{~A} * \mathrm{~B}-1.02 \mathrm{E}- \\
03 * \mathrm{~A}^{2}+2.81 \mathrm{E}-03 * \mathrm{~B}^{2}\end{array}$ \\
\hline & Transparent & $\begin{array}{c}\mathrm{T} 0=221.8-1.38 * \mathrm{~A} \\
+0.68 * \mathrm{~B}-1.87 \mathrm{E}-04 * \mathrm{~A} * \mathrm{~B} \\
+2.4 \mathrm{E}-03 * \mathrm{~A}^{2}-6.495 \mathrm{E}-03 * \\
\mathrm{~B}^{2}\end{array}$ & $\begin{array}{c}\mathrm{T} 10=107.950 .627 * \mathrm{~A}+0.48 \\
* \mathrm{~B}+4.92 \mathrm{E}-04 * \mathrm{~A} * \mathrm{~B}+1.07 \mathrm{E} \\
-03 * \mathrm{~A}^{2}-4.85 \mathrm{E}-03 * \mathrm{~B}^{2}\end{array}$ & $\begin{array}{c}\mathrm{T} 20=134.46- \\
0.77 * \mathrm{~A}+0.1 * \mathrm{~B}+7.72 \mathrm{E}- \\
04 * \mathrm{~A} * \mathrm{~B}+1.26 \mathrm{E}-03 * \mathrm{~A}^{2}- \\
6.24 \mathrm{E}-04 * \mathrm{~B}^{2}\end{array}$ & $\begin{array}{c}\mathrm{T} 40=78.76-0.35 * \mathrm{~A}- \\
0.08 * \mathrm{~B}+3.34 \mathrm{E}- \\
04 * \mathrm{~A} * \mathrm{~B}+5.42 \mathrm{E}- \\
04 * \mathrm{~A}^{2}+2.56 \mathrm{E}-03 * \mathrm{~B}^{2}\end{array}$ \\
\hline & $\begin{array}{c}\text { Bio } \\
\text { degradable }\end{array}$ & $\begin{array}{c}\mathrm{T} 0=- \\
92.05+0.83 * \mathrm{~A}+0.36 * \mathrm{~B}- \\
1.87 \mathrm{E}-04 * \mathrm{~A} * \mathrm{~B}-1.36 \mathrm{E}- \\
03 * \mathrm{~A}^{2}-2.42 \mathrm{E}-03 * \mathrm{~B}^{2} \\
\end{array}$ & $\begin{array}{c}\mathrm{T} 10=- \\
25.8+0.31 * \mathrm{~A}+0.64 * \mathrm{~B} \\
+4.92 \mathrm{E}-04 * \mathrm{~A} * \mathrm{~B}-5.53 \mathrm{E}- \\
04 * \mathrm{~A}^{2}-8.11 \mathrm{E}-03 * \mathrm{~B}^{2} \\
\end{array}$ & $\begin{array}{c}\mathrm{T} 20=- \\
18.83+0.28 * \mathrm{~A}+0.4 * \mathrm{~B} \\
+7.72 \mathrm{E}-04 * \mathrm{~A} * \mathrm{~B}-5.42 \mathrm{E}- \\
04 * \mathrm{~A}^{2}-5.47 \mathrm{E}-03 * \mathrm{~B}^{2} \\
\end{array}$ & $\begin{array}{c}\mathrm{T} 40=+.31+0.16 * \mathrm{~A}+0 . \\
15 * \mathrm{~B}-1.56 \mathrm{E}-04 * \mathrm{~A} * \mathrm{~B}- \\
3.21 \mathrm{E}-04 * \mathrm{~A}^{2}+1.25 \mathrm{E}- \\
03 * \mathrm{~B}^{2} \\
\end{array}$ \\
\hline & No mulch & $\begin{array}{c}\mathrm{T} 0=82.72-0.39 * \\
\mathrm{~A}+0.48 * \mathrm{~B}-1.87 \mathrm{E}- \\
04 * \mathrm{~A} * \mathrm{~B}+7.43 \mathrm{E}-04 * \mathrm{~A}^{2}- \\
2.84 \mathrm{E}-03 * \mathrm{~B}^{2}\end{array}$ & $\begin{array}{c}\mathrm{T} 10=6.62+0.05 * \mathrm{~A}+0.49 * \mathrm{~B} \\
+4.92 \mathrm{E}-04 * \mathrm{~A} * \mathrm{~B}-8.31 \mathrm{E}- \\
05 * \mathrm{~A}^{2}-5.14 \mathrm{E}-03 * \mathrm{~B}^{2}\end{array}$ & $\begin{array}{l}\mathrm{T} 20=39.45-0.15 * \mathrm{~A}+0.14 * \\
\mathrm{~B}+7.72 \mathrm{E}-04 * \mathrm{~A} * \mathrm{~B}+2.65 \mathrm{E}- \\
04 * \mathrm{~A}^{2}-1.75 \mathrm{E}-03 * \mathrm{~B}^{2}\end{array}$ & $\begin{array}{c}\mathrm{T} 40=55.05-0.24 * \mathrm{~A}- \\
0.1 * \mathrm{~B}+6.01 \mathrm{E}- \\
04 * \mathrm{~A} * \mathrm{~B}+4.2 \mathrm{E}-04 * \\
\mathrm{~A}^{2}+2.07 \mathrm{E}-03 * \mathrm{~B}^{2}\end{array}$ \\
\hline
\end{tabular}

The highest and lowest heat transfer rates were observed in the transparent and biodegradable mulch, respectively. So, the lowest soil temperature was recorded in transparent mulch at levels of 0 to $10 \mathrm{~cm}$, which continues to the lower levels in the same way. The radiation energy input from the soil surface, after passing through the mulch on the pathway to the soil, is used to evaporate the moisture existing in the bed. The energy used for the evaporation increases and the velocity of temperature rise in the depth decreases. 

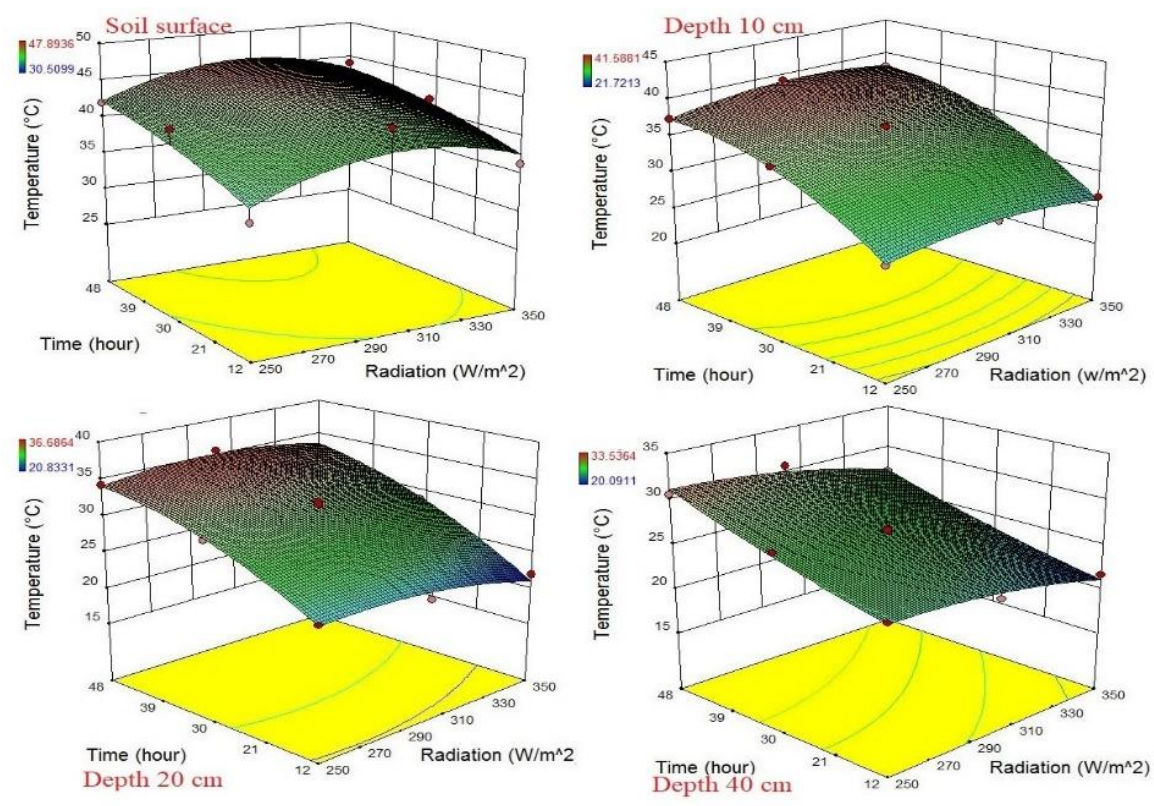

Figure 9- Soil temperature changes at different depths in biodegradable mulch

The study shows that there is a close relationship between temperature and soil moisture. Moisture can directly affect heat transfer from the surface to the depth of the soil and can change the thermal conductivity coefficient (Scarascia-Mugnozza et al. 2006). In this research, the highest temperature was observed for the dark mulch. It was assumed that the absence of covering at higher levels could increase the soil temperature more than other treatments, yet the results did not confirm this assumption. Because most of the consumed energy was dedicated to the evaporation and transfer of moisture from lower levels to the surface of the soil. Mulching decreased the moisture transfer rate and consequently the energy consumption (Yin et al. 2016). In the study by Xiukang et al. (2015), the temperature difference at high levels between coated and uncoated soils was considered by the absorption and reflection of solar electromagnetic waves (Xiukang et al. 2015). The reason for the difference in temperature between the mulches can be attributed to the optical properties, which include the coefficients of reflection, absorption and transmission of electromagnetic waves in each of them (Kasirajan \& Ngouajio 2012). As the previous research has pointed out, the conservation of thermal energy within the soil bed increases with increasing the transmissivity coefficient in long wave (middle infrared) in the mulch; a feature being visible in biodegradable mulch (Vox \& Schettini 2007). Perhaps this can justify the temperature of the uncoated soil. The temperature cannot be maintained due to the absence of these waves and the temperature of uncoated soil was observed less than the other ones. On the other hand, passing short waves (near infrared) from the mulch will direct heat energy into soil (Touchaleaume et al. 2016). The passage of these waves in the mulch without biodegradable additive was more than that of other types; therefore, the thermal energy transmission in this type of mulch increased, leading to an increase in temperature and use of energy to evaporate the process. This is evident in the dark mulch, which can be due to an increase in the rate of evaporation, and consequently, accelerating the decrease in moisture content (Moreno et al. 2016).

By inserting the carboxylic acid group used in the biodegradable additive into the polyethylene structure, the polymeric chains pore is filled, which reduces the penetration rate of water vapor and helps maintain moisture (Han \& Krochta 1999). Specific heat capacity for soil remains stable when moisture in soils, which use biodegradable mulches, is maintained. As a result, more energy is needed to increase its temperature. For this reason, the increase of temperature in soils with lower moisture content will be higher than other soils. This is because the specific heat capacity decreases (Zhang et al. 2008). The presence of more pores in the molecular structure of polyethylene, compared with the biodegradable structure, increases the permeability of water vapor in this type of coating. The loss of moisture in the soil bed accelerated the temperature rise because of its reduced specific heat capacity. As a result, higher temperatures were attainable in the soil bed with dark polyethylene coatings. It should also be noted that percentage of waves passing the near infrared and visible region of dark mulches is higher than other (Moreno et al. 2016). To have the temperature rise and degradability simultaneously, the dark color additives are suggested to be used in the compounds of biodegradable mulches.

Based on the results obtained and comparing them with the results of previous studies, it can be concluded that the use of mulch can regulate the vertical distribution of soil moisture. Moisture can be maintained because it is not evaporated on the soil surface due to the lack of porosity changes. As the high temperature of the soil accelerates and improves in the plant growth process, excessive increase in some plants, for example in corn, can bring about some problems, including leaf shrinkage and may also reduce seed filling. Also, the improvement of microbial activity in the soil and the increased rate of degradation of soil organic matter are other consequences of excessive increase of soil temperature (Zhou et al. 2012; Yin et al. 2016). Besides, soil placement at a temperature of close to $50{ }^{\circ} \mathrm{C}$ near the surface $(0$ to $10 \mathrm{~cm}$ depth) for 3 to 4 weeks in soil solarization is recommended as it reduces and manages plant diseases, and controls pathogens of the soil and weeds (Luvisi et al. 2015, 2016). 
Therefore, this research shows that the stated goal can be achieved provided that the designed system is put into practice. The increase of soil temperature and improvement of moisture conditions can lead to a better selection of the best depth of cultivation for farmers, when compared with the non-use of mulches (Subrahmaniyan \& Zhou 2008; Liu et al. 2009; Xiukang et al. 2015).

\section{Conclusions}

Considering that the evaluation of the efficiency of soil mulches in open fields requires a great deal of time, the method presented in this research and the design of the laboratory environment and the response surface method can significantly reduce the time and energy demanded to achieve the results. Also, the quality and production capabilities of the product were assured through a careful-examination of the validation test results for biodegradable mulches in accordance with the standards. Temperature and moisture content in different soil depths at the time applying the mulches significantly changed during the experiment process while this was not the case in non-mulched soil. This difference was more tangible at higher levels $(0$ to $10 \mathrm{~cm})$. Nevertheless, the amount of moisture change for transparent and degradable mulches was not significant during the experiments. The sharp temperature increase from higher levels to the lower depths of dark mulch and no coating was observed. While the temperature in the depths of the soil increased with a mild slope for transparent and biodegradable mulch. According to the results of this research and the investigations carried out in this area, given the importance of preserving the environment, the production of biodegradable mulches can facilitate the usage of the evaluation method applied in the study for a wide range of applications.

\section{Acknowledgements}

This research is the result of the investigations that is conducted at the Ferdowsi University of Mashhad and the authors would like to extend their appreciation for financial support provided by Ferdowsi University of Mashhad in the form of Research Project under Grant No. 43896 and Iran National science foundation under Grant No. 96015401.

\begin{tabular}{|ll|}
\hline Abbreviations and Symbols & \\
\hline AW & Available water \\
BHT & Butylated hydroxytoluene \\
CV & Coefficient of variation \\
DBM & Dibenzoylmethane \\
EPS & Expanded polystyrene \\
FC & Field capacity \\
FCCD & Face composition central design \\
GDD & Growth degree days \\
GDH & Growth degree hours \\
GPC & Gel permeation chromatography \\
HPS & High pressure sodium \\
LDPE & Low density polyethylene \\
Mn & The Number Average Molecular Weight \\
Mv & Viscosity Average Molecular Weight \\
Mw & The Weight Average Molecular Weight \\
Mz & Z-average molecular weight \\
PBAT & Polybutylene adipate-co-terephthalate \\
PDI & Polydispersity index \\
PHB & Polyhydroxybutyrate \\
PL GPC & Polymer laboratory gel permeation chromatography \\
PTF & Pedotransfer functions \\
PWP & Permanent wilting point \\
TCB & Trichlorobenzene \\
UV & Ultra violet \\
\hline
\end{tabular}

\section{References}

Akrami M, Ghasemi I, Azizi H, Karrabi M \& Seyedabadi M (2016). A new approach in compatibilization of the poly (lactic acid)/thermoplastic starch (PLA/TPS) blends. Carbohydrate Polymers 144: 254-262 https://doi.org/10.1016/j.carbpol.2016.02.035

ASTM (2004). D 6954. Standard Guide for Exposing and Testing Plastics that Degrade in the Environment by a Combination of Oxidation and Biodegradation https://doi.org/10.1520/d6954-04

ASTM (2006). D 2765-01. Standard Test Methods for Determination of Gel Content and Swell Ratio of Crosslinked Ethylene Plastics. West Conshohocken https://doi.org/10.1520/d2765-01r06

ASTM (2014). D 5208-14. Standard Practice for Fluorescent Ultraviolet (UV) Exposure of Photodegradable Plastics. West Conshohocken

ASTM (2018). D 3826-18. Standard Practice for Determining Degradation End Point in Degradable Polyethylene and Polypropylene Using a Tensile Test. West Conshohocken https://doi.org/10.1520/d3826-18

Bas D \& Boyaci I H (2007). Modeling and optimization II: comparison of estimation capabilities of response surface methodology with artificial neural networks in a biochemical reaction. Journal of Food Engineering 78(3): 846-854 https://doi.org/10.1016/j.jfoodeng.2005.11.025 
Boborodea A, Collignon F \& Brookes A (2015). Characterization of Polyethylene in Dibutoxymethane by High-Temperature Gel Permeation Chromatography with Triple Detection. International Journal of Polymer Analysis and Characterization 20(4): 316-322 https://doi.org/10.1080/1023666x.2015.1017038

Braunack M, Johnston D, Price J \& Gauthier, E (2015). Soil temperature and soil water potential under thin oxodegradable plastic film impact on cotton crop establishment and yield. Field Crops Research 184: 91-103 https://doi.org/10.1016/j.fcr.2015.09.009

Briassoulis D (2004). An overview on the mechanical behaviour of biodegradable agricultural films. Journal of Polymers and the Environment 12(2): 65-81 https://doi.org/10.1023/b:jooe.0000010052.86786.ef

Briassoulis D (2006). Mechanical behaviour of biodegradable agricultural films under real field conditions. Polymer Degradation and Stability 91(6): 1256-1272 https://doi.org/10.1016/j.polymdegradstab.2005.09.016

Coto B, Escola J M, Suárez I \& Caballero M J (2007). Determination of dn/dc values for ethylene-propylene copolymers. Polymer testing 26(5): 568-575 https://doi.org/10.1016/j.polymertesting.2007.02.001

Díaz-Pérez J C, Gitaitis R \& Mandal B (2007). Effects of plastic mulches on root zone temperature and on the manifestation of tomato spotted wilt symptoms and yield of tomato. Scientia Horticulturae 114(2): 90-95 https://doi.org/10.1016/j.scienta.2007.05.013

Fattahi F S (2015). Review on Production, Properties, and Applications of Poly(lactic acid) Fibers. Journal of Textile Science and Technology 5(1): $11-17$

Ham J M \& Kluitenberg G (1994). Modeling the effect of mulch optical properties and mulch-soil contact resistance on soil heating under plastic mulch culture. Agricultural and Forest Meteorology 71(3-4): 403-424 https://doi.org/10.1016/0168-1923(94)90022-1

Ham J M, Kluitenberg G \& Lamont W (1993). Optical properties of plastic mulches affect the field temperature regime. Journal of the American Society for Horticultural Science 118(2): 188-193 https://doi.org/10.21273/jashs.118.2.188

Han J \& Krochta J (1999). Wetting properties and water vapor permeability of whey-protein-coated paper. Transactions of the ASAE 42(5): 1375 https://doi.org/10.13031/2013.13300

Heißner A, Schmidt S \& von Elsner B (2005). Comparison of plastic films with different optical properties for soil covering in horticulture: test under simulated environmental conditions. Journal of the Science of Food and Agriculture 85(4): 539-548 https://doi.org/10.1002/jsfa.1862

ISO (1993). ISO 4593. Plastics - film and sheeting - Determination of thickness by mechanical scanning. British Standards Institution

Kasirajan S \& Ngouajio M (2012). Polyethylene and biodegradable mulches for agricultural applications: a review. Agronomy for Sustainable Development 32(2): 501-529 https://doi.org/10.1007/s13593-011-0068-3

Kyrikou I \& Briassoulis D (2007). Biodegradation of agricultural plastic films: a critical review. Journal of Polymers and the Environment 15(2): 125-150 https://doi.org/10.1007/s10924-007-0053-8

Liu C, Jin S, Zhou L, Jia Y, Li F, Xiong Y \& Li X (2009). Effects of plastic film mulch and tillage on maize productivity and soil parameters. European Journal of Agronomy 31(4): 241-249 https://doi.org/10.1016/j.eja.2009.08.004

Luvisi A, Panattoni A \& Materazzi A (2015). Heat treatments for sustainable control of soil viruses. Agronomy for Sustainable Development 35(2): 657-666 https://doi.org/10.1007/s13593-014-0258-x

Luvisi A, Panattoni A \& Materazzi A (2016). RFID temperature sensors for monitoring soil solarization with biodegradable films. Computers and Electronics in Agriculture 123: 135-141 https://doi.org/10.1016/j.compag.2016.02.023

Mohanty M, Sinha N K, Painuli D, Bandyopadhyay K, Hati K, Reddy K S \& Chaudhary R (2015). Modelling soil water contents at field capacity and permanent wilting point using artificial neural network for Indian soils. National Academy Science Letters 38(5): $373-377$ https://doi.org/10.1007/s40009-015-0358-4

Moreno M M, Cirujeda A, Aibar J \& Moreno C (2016). Soil thermal and productive responses of biodegradable mulch materials in a processing tomato (Lycopersicon esculentum Mill.) crop. Soil Research 54(2): 207-215 https://doi.org/10.1071/sr15065

Mortazavi S, Ghasemi I \& Oromiehie A (2013). Effect of phase inversion on the physical and mechanical properties of low density polyethylene/thermoplastic starch. Polymer testing 32(3): 482-491 https://doi.org/10.1016/j.polymertesting.2013.01.004

Papadakis G, Briassoulis D, Mugnozza G S, Vox G, Feuilloley P \& Stoffers J (2000). Review Paper (SE-Structures and Environment): Radiometric and thermal properties of, and testing methods for, greenhouse covering materials. Journal of Agricultural Engineering Research 77(1): 7-38 https://doi.org/10.1006/jaer.2000.0525

Pramanik P, Bandyopadhyay K, Bhaduri D, Bhatacharyya R \& Aggarwal P (2015). Effect of mulch on soil thermal regimes-A review. International Journal of Agriculture, Environment and Biotechnology 8(3): 645 https://doi.org/10.5958/2230-732x.2015.00072.8

Scarascia-Mugnozza G, Schettini E \& Vox G (2004). Effects of solar radiation on the radiometric properties of biodegradable films for agricultural applications. Biosystems Engineering 87(4): 479-487 https://doi.org/10.1016/j.biosystemseng.2004.01.008

Scarascia-Mugnozza G, Schettini E, Vox G, Malinconico M, Immirzi B \& Pagliara S (2006). Mechanical properties decay and morphological behaviour of biodegradable films for agricultural mulching in real scale experiment. Polymer Degradation and Stability 91(11): 2801-2808 https://doi.org/10.1016/j.polymdegradstab.2006.02.017

Schonbeck M W \& Evanylo G K (1998). Effects of Mulches on Soil Properties and Tomato Production I. Soil Temperature, Soil Moisture and Marketable Yield. Journal of Sustainable Agriculture 13(1): 55-81 10.1300/J064v13n01_06 https://doi.org/10.1300/j064v13n01_06

Shakeri Q F G F (2016). Calibration of Angstrom-Prescott Coefficients for Selected Stations of Khorasan-e Razavi Province. Water and Soil Science 26(3-2): 229-241

Sivan A (2011). New perspectives in plastic biodegradation. Current opinion in biotechnology 22(3): 422-426 https://doi.org/10.1016/j.copbio.2011.01.013

Subrahmaniyan K \& Zhou W (2008). Soil temperature associated with degradable, non-degradable plastic and organic mulches and their effect on biomass production, enzyme activities and seed yield of winter rapeseed (Brassica napus L.). Journal of Sustainable Agriculture 32(4): 611-627 https://doi.org/10.1080/10440040802394927

Takahashi Y (2007). Cellulose nanoparticles: A route from renewable resources to biodegradable nanocomposites. State University of New York College of Environmental Science and Forestry

Tindall J A, Beverly R \& Radcliffe D (1991). Mulch effect on soil properties and tomato growth using micro-irrigation. Agronomy journal 83(6): 1028-1034 https://doi.org/10.2134/agronj1991.00021962008300060019x

Touchaleaume F, Martin-Closas L, Angellier-Coussy H, Chevillard A, Cesar G, Gontard N \& Gastaldi E (2016). Performance and environmental impact of biodegradable polymers as agricultural mulching films. Chemosphere 144: 433-439 https://doi.org/10.1016/j.chemosphere.2015.09.006 
Vox G \& Schettini E (2007). Evaluation of the radiometric properties of starch-based biodegradable films for crop protection. Polymer testing 26(5): 639-651 https://doi.org/10.1016/j.polymertesting.2007.03.010

Wood C T \& Zimmer M (2014). Can terrestrial isopods (Isopoda: Oniscidea) make use of biodegradable plastics? Applied soil ecology 77: 72-79 https://doi.org/10.1016/j.apsoil.2014.01.009

Wu J, Tomba J P, Winnik M A, Farwaha R \& Rademacher J (2004). Effect of gel content on polymer diffusion in poly (vinyl acetate-codibutyl maleate) latex films. Macromolecules 37(11): 4247-4253 https://doi.org/10.1021/ma040018k

Xiukang W, Zhanbin L \& Yingying X (2015). Effects of mulching and nitrogen on soil temperature, water content, nitrate-N content and maize yield in the Loess Plateau of China. Agricultural Water Management 161: 53-64 https://doi.org/10.1016/j.agwat.2015.07.019

Yin W, Feng F, Zhao C, Yu A, Hu F, Chai Q, Gan Y \& Guo Y (2016). Integrated double mulching practices optimizes soil temperature and improves soil water utilization in arid environments. International journal of biometeorology 60(9): 1423-1437 https://doi.org/10.1007/s00484-016-1134-y

Zhang X-h, Yang H-m, Song Y-h \& Zheng Q (2012). Influence of crosslinking on physical properties of low density polyethylene. Chinese Journal of Polymer Science 30(6): 837-844 https://doi.org/10.1007/s10118-012-1194-3

Zhang Y, Han J \& Kim G (2008). Biodegradable Mulch Film Made of Starch-Coated Paper and Its Effectiveness on Temperature and Moisture Content of Soil. Communications in soil science and plant analysis 39(7-8): 1026-1040 https://doi.org/10.1080/00103620801925448

Zhou L-M, Jin S-L, Liu C-A, Xiong Y-C, Si J-T, Li X-G, Gan Y-T \& Li F-M (2012). Ridge-furrow and plastic-mulching tillage enhances maize-soil interactions: Opportunities and challenges in a semiarid agroecosystem. Field Crops Research 126: 181-188 https://doi.org/10.1016/j.fcr.2011.10.010

(C) 2021 by the authors. Licensee Ankara University, Faculty of Agriculture, Ankara, Turkey. This article is an open access article distributed under the terms and conditions of the Creative Commons Attribution (CC BY) license (http://creativecommons.org/licenses/by/4.0/). 